Marquette University

e-Publications@Marquette

$4-2019$

Synthesis of Quinazoline and Quinazolinone Derivatives via

Ligand-Promoted Ruthenium-Catalyzed Dehydrogenative and Deaminative Coupling Reaction of 2-Aminophenyl Ketones and 2-Aminobenzamides with Amines

Pandula T. Kirinde Arachchige

Chae S. Yi

Marquette University, chae.yi@marquette.edu

Follow this and additional works at: https://epublications.marquette.edu/chem_fac

Recommended Citation

Arachchige, Pandula T. Kirinde and Yi, Chae S., "Synthesis of Quinazoline and Quinazolinone Derivatives via Ligand-Promoted Ruthenium-Catalyzed Dehydrogenative and Deaminative Coupling Reaction of 2-Aminophenyl Ketones and 2-Aminobenzamides with Amines" (2019). Chemistry Faculty Research and Publications. 1002.

https://epublications.marquette.edu/chem_fac/1002 
Marquette University

e-Publications@Marquette

Chemistry Faculty Research and Publications/College of Arts and Sciences

This paper is NOT THE PUBLISHED VERSION; but the author's final, peer-reviewed manuscript. The published version may be accessed by following the link in the citation below.

Organic Letters, Vol. 21, No. 9 (April 2019) : 3337-3341. DOI. This article is @ American Chemical Society and permission has been granted for this version to appear in e-Publications@Marquette. American Chemical Society does not grant permission for this article to be further copied/distributed or hosted elsewhere without the express permission from American Chemical Society.

\section{Synthesis of Quinazoline and Quinazolinone Derivatives via Ligand-Promoted Ruthenium- Catalyzed Dehydrogenative and Deaminative Coupling Reaction of 2-Aminophenyl Ketones and 2-Aminobenzamides with Amines}

Pandula T. Kirinde Arachchige

Department of Chemistry, Marquette University, Milwaukee, Wisconsin

Chae S. Yi

Department of Chemistry, Marquette University, Milwaukee, Wisconsin 


\section{Abstract}

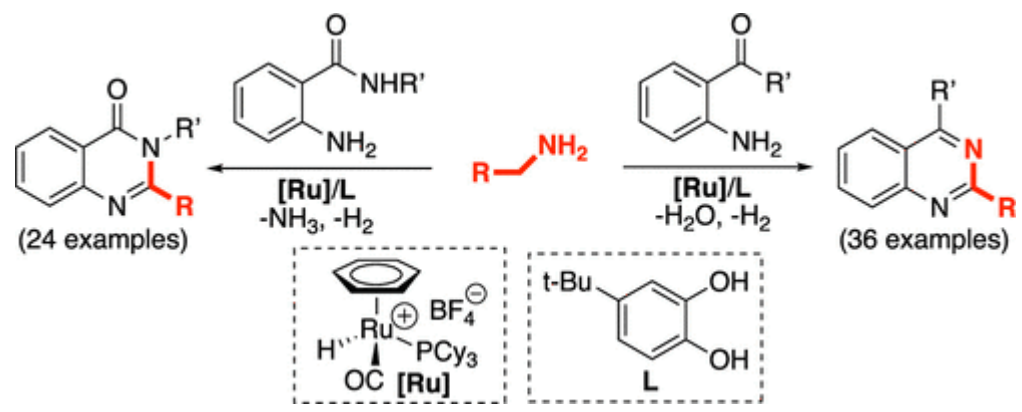

The in situ formed ruthenium catalytic system ([Ru]/L) was found to be highly selective for the dehydrogenative coupling reaction of 2-aminophenyl ketones with amines to form quinazoline products. The deaminative coupling reaction of 2-aminobenzamides with amines led to the efficient formation of quinazolinone products. The catalytic coupling method provides an efficient synthesis of quinazoline and quinazolinone derivatives without using any reactive reagents or forming any toxic byproducts.

Quinazolines and quinazolinones are a privileged class of nitrogen heterocyclic scaffolds that have been found to exhibit a broad spectrum of pharmacological activities, including anti-inflammatory, antitubercular, and antiviral activities.(1) A number of quinazoline-based drugs such as prazocin and doxazosine have been approved to treat benign prostatic hyperplasia and post-traumatic stress disorder,(2) while both erlotinib and gefitinib have been used for the treatment of lung and pancreatic cancers (igire 1).(3) Lapatinib, as an inhibitor for epidermal growth factor, has been shown to be effective in combination therapy for breast cancer.(4) Several quinazolinone-based drugs including idelalisib and fenquizone have been shown to exhibit a broad spectrum of antimicrobial, antitumor, antifungal, and cytotoxic activities.(5)

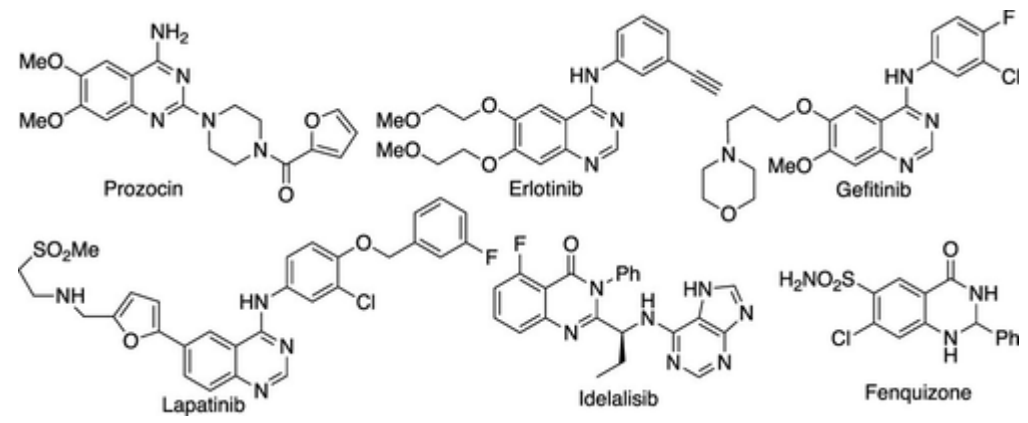

Figure 1. Selected examples of quinazoline and quinazolinone-based drugs.

A number of different synthetic strategies for quinazolines and quinazolinones have been developed over the years, in part to meet the growing needs for screening such derivatives.(6) Several research groups have successfully utilized copper-catalyzed Ullmann-type coupling methods of aryl bromides and benzamidines for the synthesis of quinazoline derivatives.(7) Similar Cu-catalyzed oxidative coupling methods of aniline derivatives with aldehydes and nitriles have also been developed for the construction of quinoline core structures.(8) Transition-metal-catalyzed oxidative $\mathrm{C}-\mathrm{H}$ amination and alkylation methods have also been successfully employed to synthesize quinazoline and quinazolinone derivatives.(9) Cho and co-workers recently devised a practical synthesis of 2-arylquinazoline derivatives from the coupling of 2-aminobezylamines with halogenated toluene substrates.(10)

Since the advent of the Niementowski condensation of anthranilic acids with amides,(11) a variety of sustainable synthetic methods have also been devised for the assembly of quinazolinone core structures.(12) Much recent research effort has been devoted to the development of catalytic coupling methods to increase efficiency and 
selectivity in constructing quinazolinone core structures. A number of transition-metal-catalyzed direct coupling methods of aminobenzamides with alcohols and carbonyl compounds have been successfully exploited to synthesize quinazolinone derivatives.(13) Transition-metal-catalyzed couplings of 2-aminobenzamides with alcohols and ketones(14) and three-component couplings of 2-aminobenzamides, aryl halides or equivalents, and isocyanides $(15)$ are among the notable examples of catalytic synthesis of quinazolinones.

We previously reported that a phenol-coordinated cationic ruthenium-hydride complex is a highly effective catalyst for mediating the hydrogenolysis of aldehydes and ketones to give the corresponding aliphatic products.(16) We subsequently devised a catalytic system generated in situ from a tetranuclear rutheniumhydride complex and a catechol ligand to promote a direct deaminative coupling of primary amines.(17) We have been exploring the coupling reactions of amines to further extend the synthetic utility of ligand-promoted catalysis, and herein, we disclose an efficient catalytic synthesis of quinazoline and quinazolinone derivatives from the dehydrogenative and deaminative coupling reactions of amino ketones and aminobenzamides with amines.

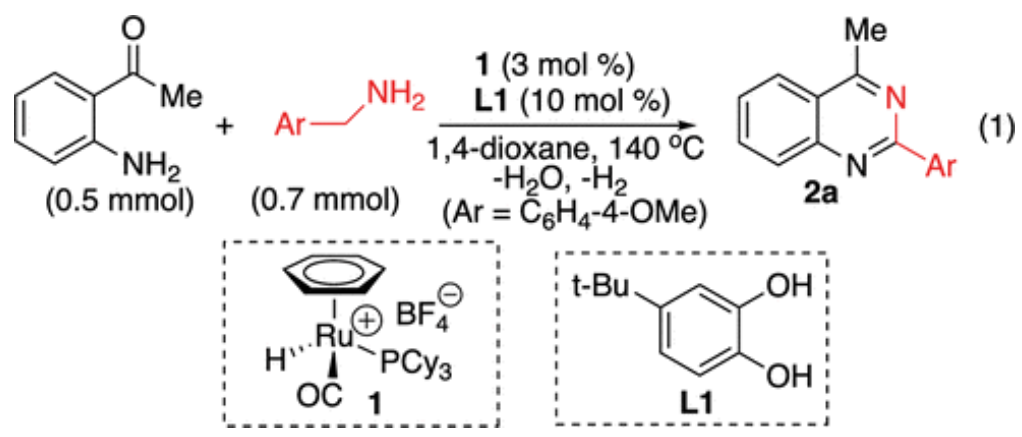

In an effort to extend the scope and utility of deaminative coupling methods, we initially explored the coupling reaction of 2-amino ketones with amines by employing the ligand-promoted catalysis protocol. Among the initially screened Ru catalysts and ligands, the in situ generated catalytic system from the cationic rutheniumhydride complex $\left[\left(\mathrm{C}_{6} \mathrm{H}_{6}\right)\left(\mathrm{PCy}_{3}\right)(\mathrm{CO}) \mathrm{RuH}^{+} \mathrm{BF}_{4}{ }^{-}\right.$(1) with 4-(1,1-dimethylethyl)-1,2-benzenediol (L1) was found to give the highest activity and selectivity for the coupling of 2-(aminophenyl)ethanone with 4methoxybenzylamine in yielding the quinazoline product $\mathbf{2 a}$ (Table S1). After further ligand screening and optimization studies, we established the standard conditions for the quinazoline product $\mathbf{2 a}$ as $\mathbf{1}(3 \mathrm{~mol} \%)$ and 4-(1,1-dimethylethyl)-1,2-benzenediol (L1) (10 mol \%) in 1,4-dioxane (2 mL) at $140{ }^{\circ} \mathrm{C}$ (eq 1).

We explored the substrate scope of the coupling reaction by using the catalyst system $\mathbf{1 / L 1}$ under the standard conditions (Table1). The coupling of 2-aminophenyl ketones with a variety of benzylic amines selectively formed the quinazoline products $\mathbf{2 a - 0}$. The coupling of 2-aminophenyl ketones with phenethylamines and with aliphatic amines also gave the selective formation of $\mathbf{2 q}, \mathbf{r}$ and $\mathbf{2 s}-\mathbf{u}$, respectively. While the coupling reaction of $2-$ aminphenyl ketone substrate with a branched amine smoothly yielded the coupling products $\mathbf{2 v}$ and $\mathbf{2 c c}$, coupling with sterically demanding secondary amines and branched amines generally yielded only a trace amount of the coupling products under the standard reaction conditions. 
Table 1. Synthesis of Quinazolines from the Coupling of 2-Aminophenyl Ketones with Amines ${ }^{\underline{a}}$
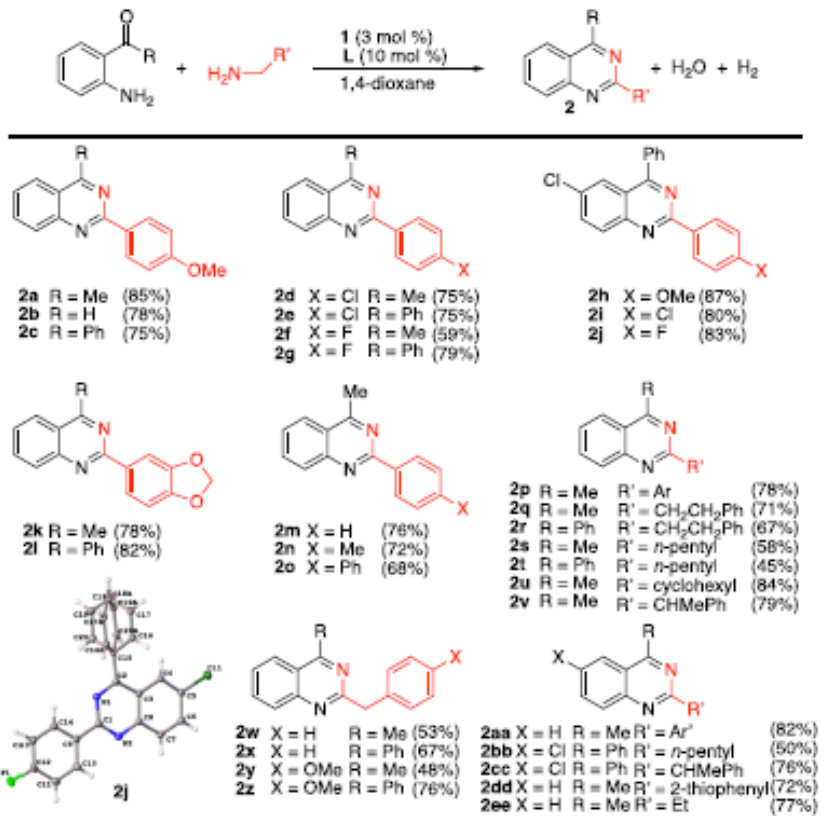

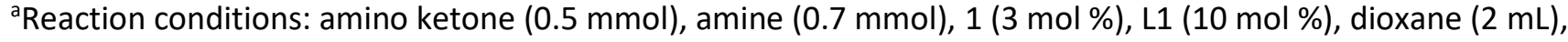
$140{ }^{\circ} \mathrm{C}, 20$ h. $\mathrm{Ar}=3,4,5$-trimethoxyphenyl, $\mathrm{Ar}^{\prime}=3,5$-methylenedioxybenzyl.

Analytically pure quinazoline products were readily isolated after silica gel column chromatographic separation, and their structures were completely established by spectroscopic methods. The structure of $\mathbf{2} \mathbf{j}$ was also confirmed by X-ray crystallography. The coupling reaction was easily scalable to a $2-3 \mathrm{mmol}$ scale reaction to yield $0.5-0.7 \mathrm{~g}$ of $\mathbf{2 b}, \mathbf{2 l}$ and $\mathbf{2 z}$. The catalytic coupling method furnishes a direct synthesis of quinazoline products without resorting to employing any reactive reagents.

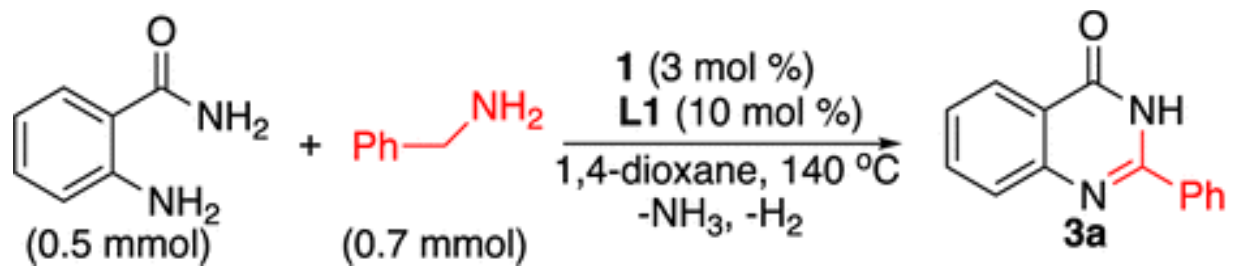

Adopting the previously developed deaminative coupling protocol, $(17)$ we next sought the catalytic coupling reaction of the arylamides with amine substrates to form quinazolinone products. Thus, the treatment of 2aminobenzamide $(0.5 \mathrm{mmol})$ with benzylamine $(0.7 \mathrm{mmol})$ in dioxane $(2 \mathrm{~mL})$ at $140{ }^{\circ} \mathrm{C}$ in the presence of the catalyst system 1 (3 mol \%)/L1 (10 mol \%) led to the selective formation of the quinazolinone product 3a, which was analyzed by both GC and NMR spectroscopic methods (eq 2).

The substrate scope of the coupling reaction was explored by using the catalyst system 1/L1 under the standard conditions (Table2). The coupling of 2-aminobenzamides with both benzyl- and alkyl-substituted amines led to the selective formation of the quinazolinone products $3 a-n$ with no significant amount of the quinazoline or other side products. The analogous coupling reaction of $\mathrm{N}$-alkyl-2-benzamides with both benzylamines and alkylsubstituted amines afforded the corresponding coupling products 30-t in moderate to high yields. 
Table 2. Synthesis of Quinazolinones from the Coupling of 2-Aminobenzamides with Amines ${ }^{\mathrm{a}}$

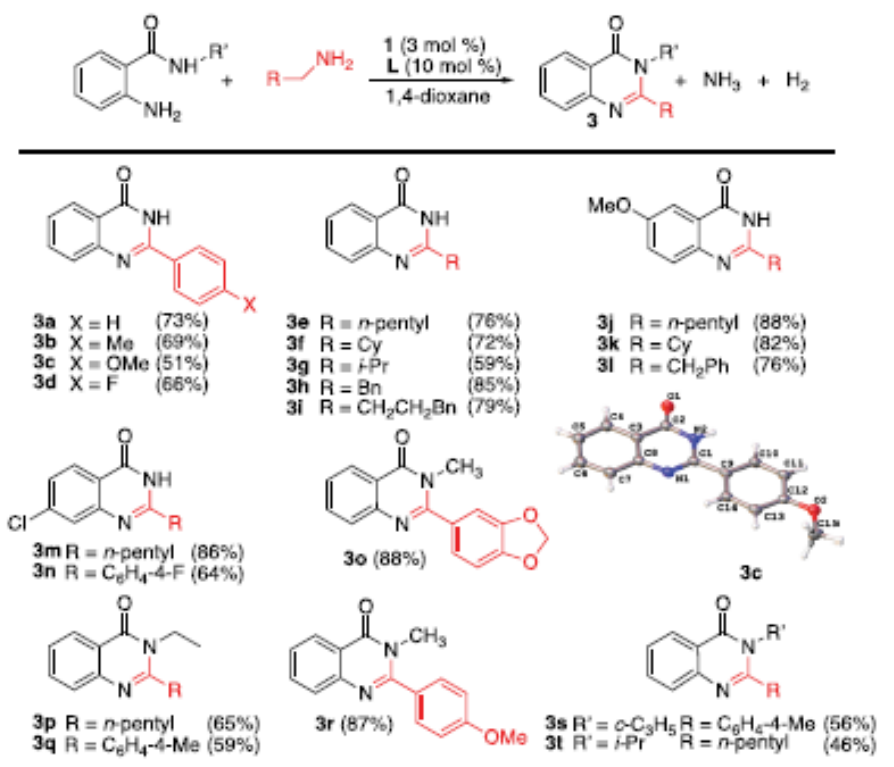

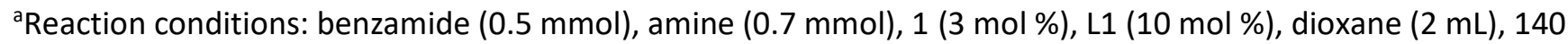
${ }^{\circ} \mathrm{C}, 20 \mathrm{~h}$.

Single crystals of $3 c$ were obtained by slow evaporation in hexanes/EtOAc at room temperature, and its structure was determined by X-ray crystallography. The formation of quinazolinone product can be rationalized by initial deaminative coupling of amide and amine substrates followed by the cyclization dehydrogenation steps. The coupling reaction efficiently assembles synthetically valuable quinazolinone core structures by employing readily available amine and benzamide substrates.

To further demonstrate synthetic utility of the catalytic method, we next performed the couplings of both 2aminophenyl ketones and 2-aminobenzamides with a number of biologically active amine substrates (Table3). The treatment of 2-aminophenylethanone with tryptamine under the standard conditions led to the indolesubstituted product $\mathbf{2} \mathbf{f f}$. The analogous coupling with (-)-cis-myrtanylamine formed the quinazoline product $2 \mathrm{gg}(\mathrm{dr}=10: 1)$ with a minimal racemization on the benzylic carbon. The coupling of 2aminophenylethanone with a morpholinyl-substituted amine predictively formed $\mathbf{2 i i}$. The coupling of a thiophene-substituted amino ketone with 3,4,5-trimethoxybenzylamine yielded the product $2 \mathrm{jj}$ in $52 \%$ yield. The analogous treatment of 2-aminobenzamide with geranylamine formed the corresponding quinazolinone product $3 \mathbf{u}$, in which the neighboring olefinic group is selectively hydrogenated, while the treatment of a thiophene-substituted amide with 4-phenylbenzylamine formed the corresponding quinazolinone product 3v. The coupling of 2-aminobenzamide with (-)-cis-myrtanylamine formed the coupling product $\mathbf{3} \mathbf{w}$ with a modest diastereoselectivity ( $d r=1.9: 1)$. In sharp contrast, the analogous coupling with $(+)$-dehydroabietylamine resulted in the formation of the coupling product $\mathbf{3 x}$ without any detectable racemization. The structure and stereochemistry of both $\mathbf{3} \mathbf{w}$ (major diastereomer) and $\mathbf{3} \mathbf{x}$ have been confirmed by X-ray crystallography.

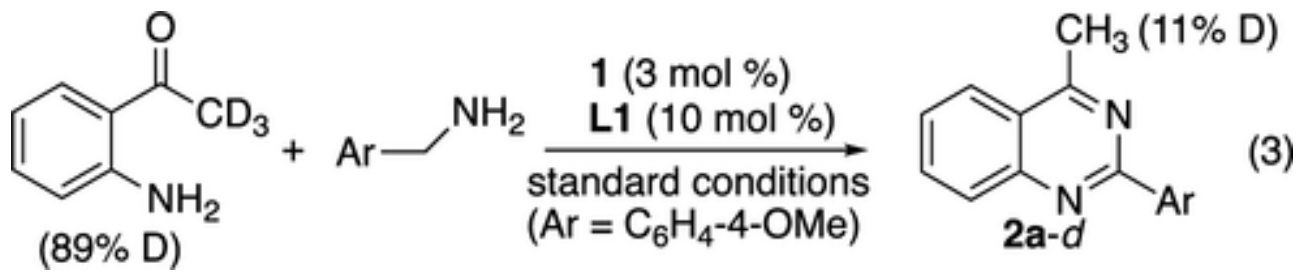


Table 3. Coupling Reaction of 2-Aminophenyl Ketones and 2-Aminobenzamides with Biologically Active Amines

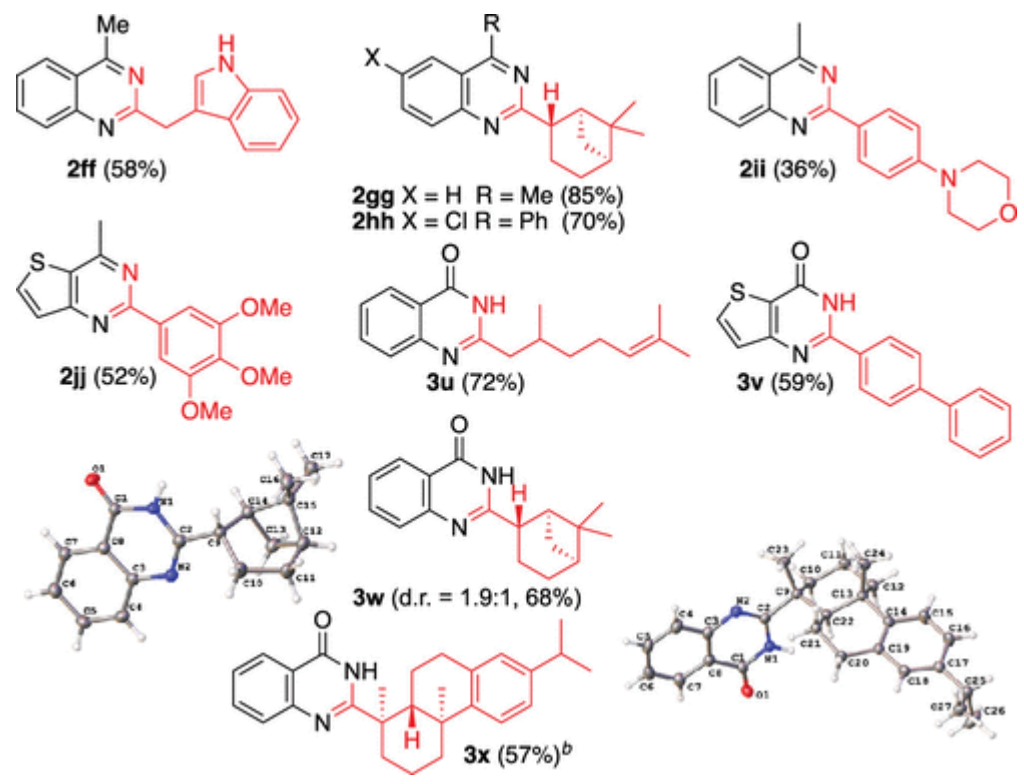

aReaction conditions: amino ketone or benzamide $(0.5 \mathrm{mmol})$, amine $(0.7 \mathrm{mmol}), 1$ (3 mol \%), $\mathbf{L}$ (10 mol \%), dioxane $(2 \mathrm{~mL}), 140^{\circ} \mathrm{C}, 20 \mathrm{~h}$.

bBenzamide $(0.25 \mathrm{mmol})$, amine $(0.35 \mathrm{mmol})$.

We performed the following set of experiments to probe mechanistic insights on the coupling reaction. First, we examined the deuterium-labeling pattern from the reaction of 2-aminophenylethanone- $d_{3}(89 \% \mathrm{D})$ with 4methoxybenzylamine (eq 3$)$. The treatment of 2-aminophenylethanone- $d_{3}(0.5 \mathrm{mmol})$ with 4-

methoxybenzylamine $(0.7 \mathrm{mmol})$ in the presence of 1 (3 mol \%)/L1 $(10 \mathrm{~mol} \%)$ in 1,4-dioxane $(2 \mathrm{~mL})$ was heated in an oil bath at $140{ }^{\circ} \mathrm{C}$ for $20 \mathrm{~h}$. The isolated product $2 \mathrm{a}-\mathrm{d}$ as analyzed by ${ }^{1} \mathrm{H}$ and ${ }^{2} \mathrm{H}$ NMR contained only $11 \%$ of the deuterium on the methyl group as most of the deuterium had been washed away (Figure S1). A relatively small amount of the deuterium on $\mathbf{2 a}-\boldsymbol{d}$ suggests an extensive keto-enol tautomerization under the reaction conditions.

We next monitored the reaction progress by using NMR spectroscopy to discern intermediate species for the coupling reaction. In a resealable NMR tube, a reaction mixture of 2-aminophenylethanone $(0.25 \mathrm{mmol})$, 4methoxybenzylamine $(0.25 \mathrm{mmol})$, and in situ generated catalyst 1 ( $3 \mathrm{~mol} \%) / \mathrm{L} 1(10 \mathrm{~mol} \%)$ in toluene- $d_{8}(0.5$ $\mathrm{mL}$ ) was immersed an oil bath set at $140{ }^{\circ} \mathrm{C}$. The tube was taken out from the oil bath at 20 min intervals, and the reaction progress was recorded by ${ }^{1} \mathrm{H}$ NMR. The appearance of new set of peaks attributed to the imine product $4 \mathrm{a}$ has been observed initially as both starting substrates are consumed. After about $100 \mathrm{~min}$ of reaction time, the peaks due to the quinazoline product $\mathbf{2 a}$ began to appear as the imine peaks gradually disappeared. The plot of relative concentration vs time is shown in Figure 2.

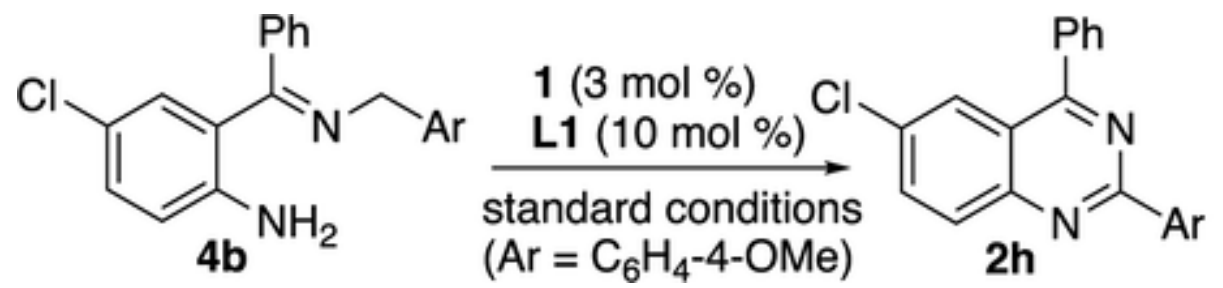




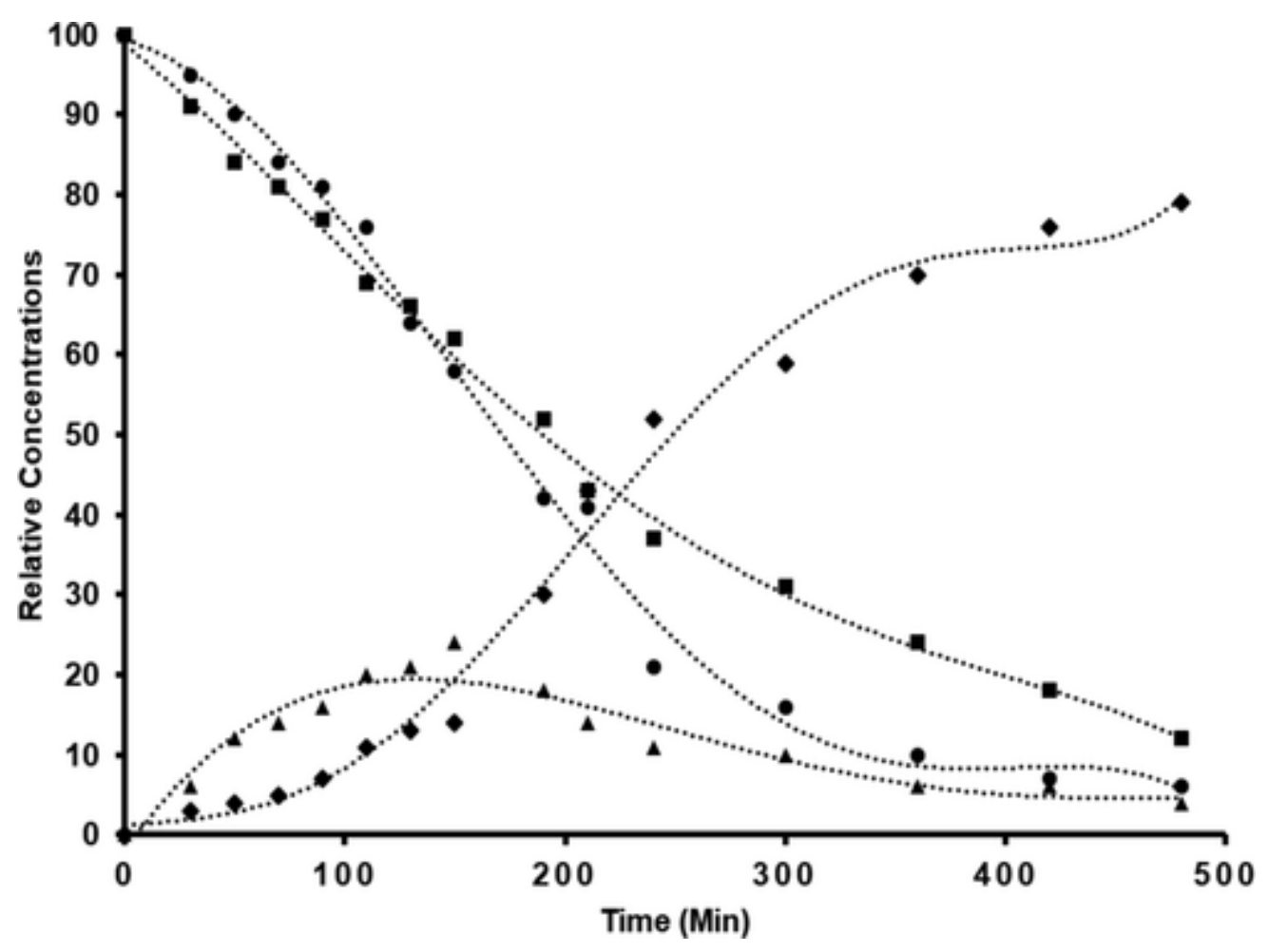

Figure 2. Plot of relative concentration vs time for the coupling reaction of 2-aminophenylethanone ( $\mathbf{\square})$ with 4methoxybenzylamine $(\bullet), 2 a(\bullet)$, and $4 a(\Delta)$.

To establish the imine as a requisite intermediate for the formation of $\mathbf{2}$, independently synthesized $\mathbf{4 b}$ was treated with $\mathbf{1 / L 1}$ under the standard conditions, which proceeded smoothly to afford the quinazoline product $\mathbf{2 h}$ in $87 \%$ yield (eq 4 ). In a control experiment, the analogous treatment of $\mathbf{4 b}$ with $p$-toluenesulfonic acid $(5 \mathrm{~mol} \%)$ did not form the product $\mathbf{2} \mathrm{h}$ under otherwise similar reaction conditions. The results showed that the ruthenium catalysis is essential for the cyclization and dehydrogenation steps of the product formation.

Although much kinetic and spectroscopic information is still needed to ascertain a detailed reaction mechanism, we offer a plausible mechanistic sequence for the formation of quinazoline products $\mathbf{2}$ on the basis of these preliminary results (Scheme 1$)$. The reaction profile study clearly implicates that the imine intermediate $\mathbf{4}$ is generated from initial dehydrative coupling of amino ketone and amine substrates. We propose that the Ru catalyst facilitates the imine isomerization to form the imine-coordinated species $\mathbf{5}$. The subsequent cyclization and dehydrogenation steps would yield the quinazoline product $\mathbf{2}$. In support of this, we previously found that the ruthenium-hydride complexes are efficient catalysts for olefin isomerization reaction(18) and dehydrogenation of saturated amines and carbonyl compounds.(19) While the exact role of catechol ligand has yet to be established, we believe that a redox-active catechol ligand may be facilitating the dehydrogenation step on the catalysis.(20) 


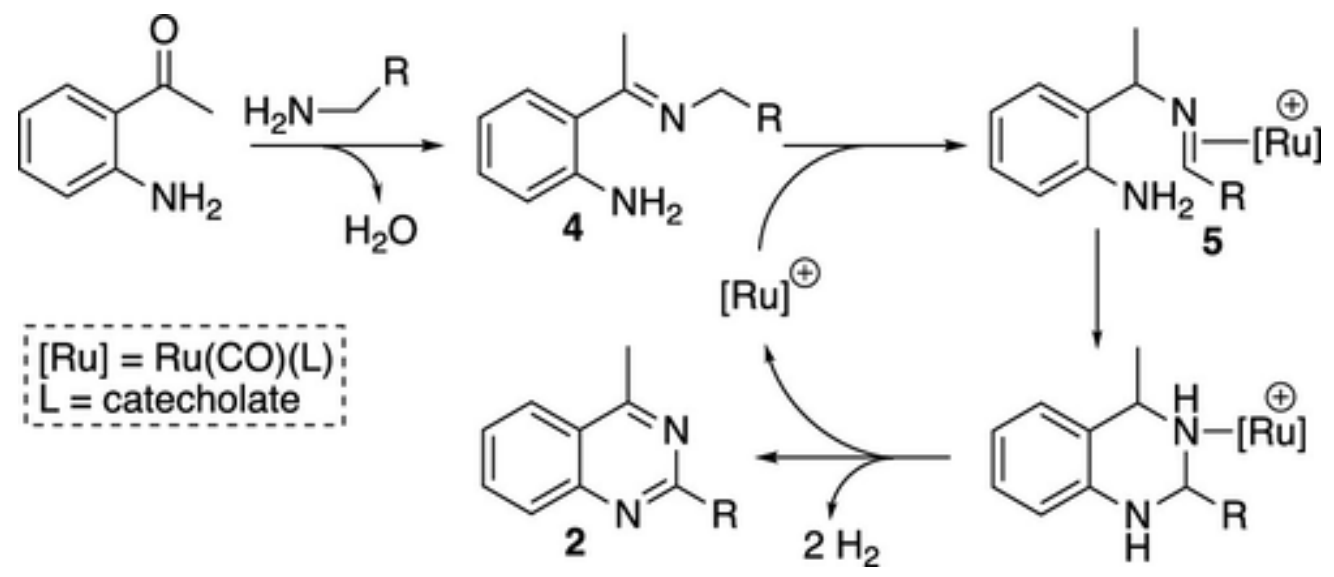

Scheme 1. Possible Mechanistic Sequence for the Formation of Quinazoline Products

In summary, we have been able to devise a catalytic protocol for the synthesis of quinazoline and quinazolinone derivatives from the dehydrogenative and deaminative couplings of 2-aminophenyl ketones and 2aminobenzamides with amines. The in situ formed ruthenium-hydride complex with a catechol ligand (1/L1) was found to exhibit uniquely high catalytic activity and selectivity in forming these products. The salient features of the catalytic method are that it employs readily available substrates, exhibits a broad substrate scope while tolerating common organic functional groups, and does not require any reactive reagents or forms any wasteful byproducts. We are currently exploring synthetic utility of the deaminative coupling protocol in constructing other nitrogen heterocyclic core structures.

\section{Supporting Information}

The Supporting Information is available free of charge on the ACS Publications website at DOI: $10.1021 /$ acs.orglett.9b01082.

Experimental procedures, spectroscopic data, and NMR spectra (PDF)

pdf

ol9b01082 si 001.pdf (10.56 MB)

\section{Accession Codes}

CCDC 1906356-1906359 contain the supplementary crystallographic data for this paper. These data can be obtained free of charge via www.ccdc.cam.ac.uk/data request/cif, or by emailing data request@ccdc.cam.ac.uk, or by contacting The Cambridge Crystallographic Data Centre, 12 Union Road, Cambridge CB2 1EZ, UK; fax: +44 1223336033.

The authors declare no competing financial interest.

\section{Terms \& Conditions}

Electronic Supporting Information files are available without a subscription to ACS Web Editions. The American Chemical Society holds a copyright ownership interest in any copyrightable Supporting Information. Files available from the ACS website may be downloaded for personal use only. Users are not otherwise permitted to reproduce, republish, redistribute, or sell any Supporting Information from the ACS website, either in whole or in part, in either machine-readable form or any other form without permission from the American Chemical Society. For permission to reproduce, republish and redistribute this material, requesters must process their 
own requests via the RightsLink permission system. Information about how to use the RightsLink permission system can be found at http://pubs.acs.org/page/copyright/permissions.html.

\section{Acknowledgments}

Financial support from the National Science Foundation (CHE-1664652) and the National Institute of Health General Medical Sciences (R15 GM109273) is gratefully acknowledged.

\section{References}

\section{Recent reviews:}

(a) Khan, I.; Ibrar, A.; Ahmed, W.; Saeed, A. Synthetic approaches, functionalization and therapeutic potential of quinazoline and quinazolinone skeletons: The advances continue. Eur. J. Med. Chem. 2015, 90, 124169, DOI: 10.1016/j.ejmech.2014.10.084.

(b) Gupta, T.; Rohilla, A.; Pathak, A.; Akhtar, M. J.; Haider, M. R.; Yar, M. S. Current perspectives on quinazolines with potent biological activities: A review. Synth. Commun. 2018, 48, 1099-1127, DOI: 10.1080/00397911.2018.1431282

2 (a) Akduman, B.; Crawford, E. D. Terazosin, doxazosin, and prazosin: current clinical experience. Urology 2001, 58, 49-54, DOI: 10.1016/S0090-4295(01)01302-4.

(b) McConnell, J. D.The long-term effect of doxazosin, finasteride, and combination therapy on the clinical progression of benign prostatic hyperplasia. N. Engl. J. Med. 2003, 349, 2387-2398, DOI: 10.1056/NEJMoa030656

3 (a) Pao, W.; Miller, V. A. Epidermal growth factor receptor mutations, small-molecule kinase inhibitors, and non-small-cell lung cancer: current knowledge and future directions. J. Clin. Oncol. 2005, 23, 25562568, DOI: 10.1200/JCO.2005.07.799.

(b) Miller, V. A.Bronchioloalveolar pathologic subtype and smoking history predict sensitivity to gefitinib in advanced non-small-cell lung cancer. J. Clin. Oncol. 2004, 22, 1103-1109, DOI: 10.1200/JCO.2004.08.158

4 (a) Geyer, C. E.; Forster, J.; Lindquist, D.; Chan, S.; Romieu, C. G.; Pienkowski, T.; Jagiello-Gruszfeld, A.; Crown, J.; Chan, A.; Kaufman, B.; Skarlos, D.; Campone, M.; Davidson, N.; Berger, M.; Oliva, C.; Rubin, S. D.; Stein, S.; Cameron, D. Lapatinib plus capecitabine for HER2-positive advanced breast cancer. N. Engl. J. Med. 2006, 355, 2733-2743, DOI: 10.1056/NEJMoa064320.

(b) Johnston, S.; Pippen, Jr. J.; Pivot, X.; Lichinitser, M.; Sadeghi, S.; Dieras, V.; Gomez, H. L.; Romieu, G.; Manikhas, A.; Kennedy, M. J.; Press, M. F.; Maltzman, J.; Florance, A.; O’Rourke, L.; Oliva, C.; Stein, S.; Pegram, M. Lapatinib combined with letrozole versus letrozole and placebo as first-line therapy for postmenopausal hormone receptor-positive metastatic breast cancer. J. Clin. Oncol. 2009, 27, 55385546, DOI: 10.1200/JCO.2009.23.3734

5 (a) Amin, K. M.; Kamel, M. M.; Anwar, M. M.; Khedr, M.; Syam, Y. M. Synthesis biological evaluation and molecular docking of novel series of spiro[(2H,3H)quinazoline-2, $1^{\prime}$-cyclohexan]-4(1H)-one derivatives as anti-inflammatory and analgesic agents. Eur. J. Med. Chem. 2010, 45, 2117- 2131, DOI: 10.1016/j.ejmech.2009.12.078.

(b) Furman, R. R.Idelalisib and rituximab in relapsed chronic lymphocytic leukemia. N. Engl. J. Med. 2014, 370, 997- 1007, DOI: 10.1056/NEJMoa1315226.

(c) Kshirsagar, U. A. Recent developments in the chemistry of quinazolinone alkaloids. Org. Biomol. Chem. 2015, 13, 9336-9352, DOI: 10.1039/C5OB01379H

6 (a) Connolly, D. J.; Cusack, D.; O'Sullivan, T. P.; Guiry, P. J. Synthesis of quinazolinones and quinazolines. Tetrahedron 2005, 61, 10153-10202, DOI: 10.1016/j.tet.2005.07.010.

(b) Khan, I.; Ibrar, A.; Abbas, N.; Saeed, A. Recent advances in the structural library of functionalized quinazoline and quinazolinone scaffolds. Synthetic approaches and multifarious applications. Eur. J. Med. Chem. 2014, 76, 193-244, DOI: 10.1016/j.ejmech.2014.02.005 
7 (a) Liu, X.; Fu, H.; Jiang, Y.; Zhao, Y. A Simple and Efficient Approach to Quinazolinones under Mild CopperCatalyzed Conditions. Angew. Chem., Int. Ed. 2009, 48, 348- 351, DOI: 10.1002/anie.200804675.

(b) Wang, C.; Li, S.; Liu, H.; Jiang, Y.; Fu, H. J. Copper-Catalyzed Synthesis of Quinazoline Derivatives via UllmannType Coupling and Aerobic Oxidation. J. Org. Chem. 2010, 75, 7936- 7938, DOI: 10.1021/jo101685d.

(c) Xu, W.; Jin, Y.; Liu, H.; Jiang, Y.; Fu, H. Copper-Catalyzed Domino Synthesis of Quinazolinones via UllmannType Coupling and Aerobic Oxidative C-H Amidation. Org. Lett. 2011, 13, 1274-1277, DOI: 10.1021/ol1030266.

(d) Malakar, C. C.; Baskakova, A.; Conrad, J.; Beifuss, U. Copper-Catalyzed Synthesis of Quinazolines in Water Starting from o-Bromobenzylbromides and Benzamidines. Chem. - Eur. J. 2012, 18, 8882-8885, DOI: 10.1002/chem.201200583.

(e) Omar, M. A.; Conrad, J.; Beifuss, U. Copper-catalyzed domino reaction between 1-(2halophenyl)methanamines and amidines or imidates for the synthesis of 2-substituted quinazolines. Tetrahedron 2014, 70, 3061-3072, DOI: 10.1016/j.tet.2014.02.066

8 (a) Han, B.; Yang, X.-L.; Wang, C.; Bai, Y.-W.; Pan, T.-C.; Chen, X.; Yu, W. CuCl/DABCO/4-HO-TEMPO-Catalyzed Aerobic Oxidative Synthesis of 2-Substituted Quinazolines and 4H-3,1-Benzoxazines. J. Org. Chem. 2012, 77, 1136- 1142, DOI: 10.1021/jo2020399.

(b) Chen, Z.; Chen, J.; Liu, M.; Ding, J.; Gao, W.; Huang, X.; Wu, H. Unexpected Copper-Catalyzed Cascade Synthesis of Quinazoline Derivatives. J. Org. Chem. 2013, 78, 11342-11348, DOI: 10.1021/jo401908g.

(c) Liu, Q.; Zhao, Y.; Fu, H.; Cheng, C. Copper-Catalyzed Sequential N-Arylation and Aerobic Oxidation: Synthesis of Quinazoline Derivatives. Synlett 2013, 24, 2089- 2094, DOI: 10.1055/s-0033-1339800.

(d) Wang, X.; He, D.; Huang, Y.; Fan, Q.; Wu, W.; Jiang, H. Copper-Catalyzed Synthesis of Substituted Quinazolines from Benzonitriles and 2-Ethynylanilines via Carbon-Carbon Bond Cleavage Using Molecular Oxygen. J. Org. Chem. 2018, 83, 5458- 5446, DOI: 10.1021/acs.joc.8b00378

9 (a) Wiedemann, S. H.; Ellman, J. A.; Bergman, R. G. Rhodium-Catalyzed Direct C-H Addition of 3,4Dihydroquinazolines to Alkenes and Their Use in the Total Synthesis of Vasicoline. J. Org. Chem. 2006, 71, 1969- 1976, DOI: 10.1021/jo052345b.

(b) Mohammed, S.; Vishwakarma, R. A.; Bharate, S. B. lodine Catalyzed Oxidative Synthesis of Quinazolin-4(3H)ones and Pyrazolo[4,3-d]pyrimidin-7(6H)-ones via Amination of sp3 C-H Bond. J. Org. Chem. 2015, 80, 6915-6921, DOI: 10.1021/acs.joc.5b00989.

(c) Wang, X.; Jiao, N. Rh- and Cu-Cocatalyzed Aerobic Oxidative Approach to Quinazolines via [4 + 2] C-H Annulation with Alkyl Azides. Org. Lett. 2016, 18, 2150- 2153, DOI: 10.1021/acs.orglett.6b00774.

(d) Gutiérrez-Bonet, Á; Remeur, C.; Matsui, J. K.; Molander, G. A. Late-Stage C-H Alkylation of Heterocycles and 1,4-Quinones via Oxidative Homolysis of 1,4-Dihydropyridines. J. Am. Chem. Soc. 2017, 139, 1225112258, DOI: 10.1021/jacs.7b05899

10 Chatterjee, T.; Kim, D. I.; Cho, E. J. Base-Promoted Synthesis of 2-Aryl Quinazolines from 2Aminobenzylamines in Water. J. Org. Chem. 2018, 83, 7423- 7430, DOI: 10.1021/acs.joc.8b00327

11 (a) Williamson, T. A. The chemistry of quinazoline. In Heterocyclic Compounds; Elderfield, R. C., Ed.; John Wiley \& Sons: New York, 1957; Vol. 6, pp 324-376.

(b) Ferrini, S.; Ponticelli, F.; Taddei, M. Convenient Synthetic Approach to 2,4-Disubstituted Quinazolines. Org. Lett. 2007, 9, 69- 72, DOI: 10.1021/ol062540s.

(c) Hensbergen, A. W.; Mills, V. R.; Collins, I.; Jones, A. M. An expedient synthesis of oxazepino and oxazocino quinazolines. Tetrahedron Lett. 2015, 56, 6478-6483, DOI: 10.1016/j.tetlet.2015.10.008

12 (a) Martins, M. A. P.; Frizzo, C. P.; Moreira, D. N.; Buriol, L.; Machado, P. Solvent-Free Heterocyclic Synthesis. Chem. Rev. 2009, 109, 4140- 4182, DOI: 10.1021/cr9001098.

(b) Candeias, N. R.; Branco, L. C.; Gois, P. M. P.; Afonso, C. A. M.; Trindade, A. F. More Sustainable Approaches for the Synthesis of N-Based Heterocycles. Chem. Rev. 2009, 109, 2703-2802, DOI: 10.1021/cr800462w

13 (a) Xu, L.; Jiang, Y.; Ma, D. Synthesis of 3-Substituted and 2,3-Disubstituted Quinazolinones via Cu-Catalyzed Aryl Amidation. Org. Lett. 2012, 14, 1150-1153, DOI: 10.1021/ol300084v. 
(b) Wei, H.; Li, T.; Zhou, Y.; Zhou, L.; Zeng, Q. Copper-Catalyzed Domino Synthesis of Quinazolin-4(3H)-ones from (Hetero)arylmethyl Halides, Bromoacetate, and Cinnamyl Bromide. Synthesis 2013, 45, 3349- 3354, DOI: 10.1055/s-0033-1340040.

(c) Li, F.; Lu, L.; Liu, P. Acceptorless Dehydrogenative Coupling of o-Aminobenzamides with the Activation of Methanol as a C1 Source for the Construction of Quinazolinones. Org. Lett. 2016, 18, 2580-2583, DOI: 10.1021/acs.orglett.6b00925.

(d) Upadhyaya, K.; Thakur, R. K.; Shukla, S. K.; Tripathi, R. P. One-Pot Copper(I)-Catalyzed Ligand/Base-Free Tandem Cyclooxidative Synthesis of Quinazolinones. J. Org. Chem. 2016, 81, 5046- 5055, DOI: 10.1021/acs.joc.6b00599

14 (a) Siddiki, S. M. A.; Kon, K.; Touchy, A. S. A. T.; Shimizu, K. Direct synthesis of quinazolinones by acceptorlessdehydrogenative coupling of o-aminobenzamide and alcohols by heterogeneous $\mathrm{Pt}$ catalysts. Catal. Sci. Technol. 2014, 4, 1716-1719, DOI: 10.1039/C4CY00092G.

(b) Zhang, W.; Meng, C.; Liu, Y.; Tang, Y.; Li, F. Auto-Tandem Catalysis with Ruthenium: From oAminobenzamides and Allylic Alcohols to Quinazolinones via Redox Isomerization/Acceptorless Dehydrogenation. Adv. Synth. Catal. 2018, 360, 3751-3759, DOI: 10.1002/adsc. 201800660

15 (a) Jiang, X.; Tang, T.; Wang, J.-M.; Chen, Z.; Zhu, Y.-M.; Ji, S.-J. Palladium-Catalyzed One-Pot Synthesis of Quinazolinones via tert-Butyl Isocyanide Insertion. J. Org. Chem. 2014, 79, 5082- 5087, DOI: 10.1021/jo500636y.

(b) Qian, C.; Liu, K.; Tao, S.-W.; Zhang, F.-L.; Zhu, Y.-M.; Yang, S.-L. Palladium-Catalyzed Oxidative ThreeComponent Coupling of Anthranilamides with Isocyanides and Arylboronic Acids: Access to 2,3Disubstituted Quinazolinones. J. Org. Chem. 2018, 83, 9201-9209, DOI: 10.1021/acs.joc.8b01218

16 Kalutharage, N.; Yi, C. S. Scope and Mechanistic Analysis for Chemoselective Hydrogenolysis of Carbonyl Compounds Catalyzed by a Cationic Ruthenium-Hydride Complex with Tunable Phenol Ligand. J. Am. Chem. Soc. 2015, 137, 11105-11114, DOI: 10.1021/jacs.5b06097

17 Arachchige, P. T. K.; Lee, H.; Yi, C. S. Synthesis of Symmetric and Unsymmetric Secondary Amines from the Ligand Promoted Ruthenium Catalyzed Deaminative Coupling Reaction of Primary Amines. J. Org. Chem. 2018, 83, 4932- 4947, DOI: 10.1021/acs.joc.8b00649

18 Yi, C. S.; Lee, D. W. Regioselective Intermolecular Coupling Reaction of Arylketones and Alkenes Involving C-H Bond Activation Catalyzed by an in-Situ Formed Cationic Ruthenium-Hydride Complex. Organometallics 2009, 28, 4266-4268, DOI: 10.1021/om900416k

19 Yi, C. S.; Lee, D. W. Efficient Dehydrogenation of Amines and Carbonyl Compounds Catalyzed by a Tetranuclear Ruthenium- $\mu$-oxo- $\mu$-hydroxo-hydride Complex. Organometallics 2009, 28, 947-949, DOI: 10.1021/om8010883

20 Broere, D. L. J.; Plessius, R.; Van der Vlugt, J. I. New avenues for ligand-mediated processes-expanding metal reactivity by the use of redox-active catechol, o-aminophenol and o-phenylenediamine ligands. Chem. Soc. Rev. 2015, 44, 6886-6915, DOI: 10.1039/C5CS00161G 